\title{
The effects of emotion on tip-of-the-tongue states
}

\author{
BenNetT L. SCHWARTZ \\ Florida International University, Miami, Florida
}

\begin{abstract}
Tip-of-the-tongue states (TOTs) are judgments of the likelihood of imminent retrieval for items currently not recalled. In the present study, the relation of emotion to the experience of TOTs is explored. Emotion-inducing questions (e.g., "What is the term for ritual suicide in Japan?") were embedded among neutral questions (e.g., "What is the capital of Denmark?"). Participants attempted to recall the answers and, if unsuccessful, were asked if they were in a TOT and given a recognition test. For unrecalled items, there were significantly more TOTs for the emotional items than for the neutral items, even though the recognition performance was identical. There were more TOTs for questions that followed emotional questions than TOTs for questions that followed neutral questions, suggesting the emotional arousal lasts beyond the specific question. These findings suggest that emotional cues increase the likelihood of TOTs. These data are consistent with a metacognitive view of TOTs.
\end{abstract}

The signs of it [TOT] were unmistakable; he would appear to be in mild torment, something like the brink of a sneeze, and if he found the word his relief was considerable.

\section{R. Brown and McNeill (1966, p. 326)}

The tip-of-the-tongue state (TOT) is the feeling that a currently inaccessible item will be recalled (R. Brown \& McNeill, 1966; see A. S. Brown, 1991; Schwartz, 2002, 2006; and Smith, 1994, for reviews). As the quote from R. Brown and McNeill suggests, many anecdotal reports associate TOTs with the experience of emotion. However, the relation, if any, between emotion and TOTs has seldom been explored in empirical studies. It is unknown, for example, whether people experience TOTs more often when they are already emotionally aroused or if TOTs themselves induce strong emotional arousal. The present study demonstrated the role of emotional stimuli in people's experience of TOTs. The relation between memory and emotion is an old and important one (Kensinger \& Schacter, 2008). In other domains, research has shown that emotion can influence memory variables, such as the amount recalled in older adults (Kensinger, 2009) or attributions of nostalgia (Leboe \& Ansons, 2006).

Two empirical studies addressed the nature of TOTs and emotion, and both are correlational. Schwartz, Travis, Castro, and Smith (2000) asked participants to ascribe an emotional state to a TOT and then correlated emotionality judgments with objective measures of performance. Participants answered general information questions and were asked to judge whether they were in a TOT for unrecalled questions. If they indicated that they were in a TOT, they were then asked whether or not an emotional feeling or a feeling of frustration accompanied the TOT. Later, they were given a second chance to recall the answer, and if they could not, they were given a recognition test. Slightly more than half $(55 \%)$ of all TOTs were judged to be emotional. Emotional TOTs were more likely to be recalled later and were recognized later than were TOTs that were not judged to be emotional. Schwartz et al. showed that participants readily ascribe emotions to TOTs and that experiencing emotion was predictive of later objective memory performance.

Schwartz (2001) also asked for emotion judgments following a TOT report. Participants had to decide whether each TOT was emotionally frustrating, emotionally exciting, or neither. TOTs were more likely to be judged as frustrating $(59 \%)$ rather than exciting $(7 \%)$. The remaining TOTs (34\%) were not accompanied by emotion. Schwartz (2001) also demonstrated the relation between TOTs and emotions. It also suggested that the emotion experienced by participants is, by and large, negative.

In the present study, emotion is elicited by uncomfortable questions, related to topics likely to be considered negative. It is unclear how emotion produced by these questions is related to the emotion experienced during TOTs. It is possible that they have nothing to do with each other, but it is also possible that emotion elicited by questions will be attributed to the emotion associated with a TOT. Although there is little research to guide the present study, that emotion may affect TOT rates is consistent with metacognitive theory.

Turning to the theories that have guided TOT research, many researchers have assumed that TOTs derive from breakdowns in lexical retrieval (see Gollan \& Brown, 2006; Vigliocco, Antonini, \& Garrett, 1997). In this view, TOTs result from incomplete or inactive links between semantic and phonological nodes in the representation of

B. Schwartz bennett.schwartz@fiu.edu 
words (see Galdo-Alvarez, Lindin, \& Díaz, 2009). From this perspective, emotion and TOTs have little in common: The TOT is simply the breakdown in the retrieval process, not one's experience of it. In contrast, the metacognitive perspective claims that TOTs are feelings of temporary inaccessibility, not the actual state of temporary inaccessibility (Brennen, Vikan, \& Dybdahl, 2007; see Schwartz, 2006). In this view, the TOT is a heuristic that informs our cognitive system if it is likely that items are accessible in memory (Metcalfe, Schwartz, \& Joaquim, 1993). If this is true, emotionality may be part of the subjective experience of a TOT. Moreover, experiencing emotion may be a factor in what drives the experience of the TOT in the first place. Earlier work has shown that cues that are more familiar induce TOTs (Metcalfe et al., 1993); it may be that cues that are more emotional also induce more TOTs. If that is so, inducing emotion in participants may affect the likelihood of experiencing a TOT. In the present experiment, emotion-inducing questions were given in the expectation that the emotion produced by the questions would be mistaken for the experience of the TOT, and more TOTs would be observed for emotional items than for nonemotional items.

In the experiment, two sets of general-information questions were used. The first, derived from the Nelson and Narens (1980) norms, were neutral questions about geography, history, sports, and other topics (e.g., "What is the capital of Denmark?"). A new set of questions was constructed to elicit emotional responses in participants (see the Appendix). These questions were about sex, disease, bodily functions, violence, and profanity. Pilot testing indicated that the emotional items were equally as difficult as the neutral questions but elicited greater judgments of emotional response.

Participants were given a mix of neutral and emotional questions to answer, with the neutral questions outnumbering the emotional questions by a 4-to-1 ratio. If they did not recall the answer to the question, participants were asked if they were experiencing a TOT. They were also asked to judge how emotional the question made them feel and how frustrated they were with their inability to answer the question. Following the judgments, the participants then saw the question again, followed by four alternatives, one of which was the correct answer. The participants then indicated which alternative they thought was correct.

The hypothesis was that participants would make more TOT judgments for emotional questions than for neutral questions. Similarly, items that elicited TOTs would also be given higher emotionality judgments than would unrecalled items that did not induce TOTs. Both of these effects should occur without emotionality actually affecting memory: Recall and recognition should not be affected by emotionality.

\section{METHOD}

\section{Participants}

The participants were 30 Florida International University students who received course credit for participating. Each was tested individually on a Macintosh computer during a session that lasted approximately $1 \mathrm{~h}$.

\section{Materials}

SuperLab 4 software was used to run the experiment and collect data. The neutral stimuli for the experiment were 79 generalinformation questions taken from the Nelson-Narens norms (Nelson \& Narens, 1980). For example, one question was "For which country is the rupee the monetary unit? (India)." Previous testing indicated that the 79 questions generated a percentage-correct rate of around $36 \%$ (with a range from $0 \%$ to $80 \%$ ) in the student population tested (see Schwartz, 2001, 2008; Schwartz et al., 2000). The emotional stimuli consisted of 20 questions (see the Appendix). I compared recall and emotionality judgments of these items to the neutral set in a pilot study, which was done in a group setting with a large undergraduate class. The questions were presented in a PowerPoint presentation. If the participants knew the answer to each question, they wrote it down. For each question, they also rated the emotion it elicited on the same scale used here. The pilot study found a recall rate of $33 \%$ for the emotional questions, not significantly different from the $35 \%$ recall rate for neutral questions $(n=67)$. However, as will be apparent below, in the main study, the emotional items were more difficult than were neutral questions. Pilot testing also demonstrated that the emotional questions were given higher ratings of emotion than were a random sample of 20 of the neutral questions $[t(66)=5.78 ; 3.1$ vs. 2.2]. Although the emotional items did not induce strong emotions, the pilot study showed that they did induce a greater emotional response than neutral items did.

In the main study, the 20 emotional items were distributed randomly among the 79 neutral questions. The list of items was randomized for each participant.

\section{Procedure}

Participants were first given detailed instructions about the procedure. They were told that they would be answering a series of general-information questions. It was explained to them that the term tip of the tongue meant that "you feel that you know the target answer and will recall it soon." Participants were encouraged, rather than to guess, to indicate that they did not know on any particular trial. Participants were instructed that they could pace themselves.

The experimenter then started the computer program that ran the experiment. Each question appeared in the middle of the screen, and a prompt appeared beneath the question. If the participant decided to answer the question, he or she said the answer aloud, and the experimenter typed it in. After giving a correct response, the participant moved on to the next question.

If the participant indicated that he or she did not know the correct answer (i.e., an omission error), the computer program asked the participant if he or she was experiencing a TOT. Incorrect answers were not followed by TOT judgments. The experimenter typed in a " $Y$ " if the participant experienced a TOT and an " $\mathrm{N}$ " if the participant did not. After the TOT judgments, the participant made a judgment as to whether the question induced emotion ("Did the question cause you to feel emotional - either positive or negative?"). Participants responded on a 5-point Likert scale, with $5=$ most emotional and $1=$ least emotional. That is, the scale measured the strength of the emotion only, not its valence. After the emotionality judgment, participants made a frustration judgment, indicating how frustrated they felt that they could not recall the answer ("Do you feel frustrated by your inability to recall the target?"). Participants responded on a 5-point Likert scale, with $5=$ most frustrated and $1=$ least frustrated.

Participants were then given a recognition test for the questions. They were shown the question followed by four alternatives, one of which was the correct answer (from Wilkinson \& Nelson, 1984, for the neutral questions). A number accompanied each alternative. Participants spoke the number associated with the answer that they thought was correct, and the experimenter typed it in. The recognition distractors were all close associates or potentially correct answers. For example, for the question "What was the last name of the first person on the moon?" all of the distractors were other astronauts from the same time period. Following the recognition phase, the participant moved on to the next recall question. 


\section{RESULTS}

\section{Procedures for Analysis}

Statistical reliability was measured at $p<.05$. There was one independent within-subjects variable: type of question (neutral vs. emotional). Additional analyses were done with the presence or absence of a TOT as a quasiindependent variable with two levels: TOT and n-TOT, respectively. Raw data for the experiment described here are available from the author.

\section{Recall and Recognition}

For neutral questions, recall was $36 \%$; but for emotional questions, it was $24 \%$. This difference was significant $\left[F(1,29)=43.5, M S_{\mathrm{e}}=0.25, \eta^{2}=.60\right]$. It is unclear why the recall for emotional questions was lower than in the pilot study.

Recognition performance was identical for neutral and emotional questions $(F<1)$. In each condition, participants correctly recognized $46 \%$ of the unrecalled targets. This was important, because it meant that the set of questions on which TOTs were made was equally well known for both emotional and neutral questions. Recognition performance, although low, was significantly higher than chance performance $[25 \% ; t(29)=21.9$ for neutral questions; $t(29)=20.6$ for emotional questions].

\section{TOTs}

TOTs were determined by examining TOT rates - the percentages of TOTs with respect to the total number of unanswered questions. Participants experienced more TOTs for emotional questions (36\%) than they did for neutral questions $\left[28 \% ; F(1,29)=22.7, M S_{\mathrm{e}}=0.08\right.$, $\left.\eta^{2}=.44\right]$. Thus, the first hypothesis was supportedthat participants are more likely to experience TOTs for emotion-inducing questions than for neutral questions.

TOTs were better predictors of recognition than were n-TOTs, consistent with the vast majority of TOT research (see Schwartz, 2002). In the present study, TOTs were followed by higher recognition performance than were n-TOTs $\left[F(1,29)=120.9, M S_{\mathrm{e}}=0.04, \eta^{2}=.81\right]$. As stated above, there was no difference in recognition performance between the neutral and emotional questions $(F<1)$, but there was a significant interaction between type of question and the presence or absence of a TOT $\left[F(1,29)=17.1, M S_{\mathrm{e}}=0.03, \eta^{2}=.37\right]$. Recognition performance was superior for emotional TOTs relative to neutral TOTs (see Table 1). That is, the TOTs for emotional questions were more accurate at predicting recognition performance than were TOTs for neutral questions.

Table 1

Emotionality Ratings, Frustration, and Recognition As a Function of Experimental Condition and the Presence or Absence of a TOT State

\begin{tabular}{llcccc}
\hline & \multicolumn{2}{c}{ Emotional } & & \multicolumn{2}{c}{ Neutral } \\
\cline { 2 - 3 } \cline { 5 - 6 } Judgment & TOTs & N-TOTs & & TOTs & N-TOTs \\
\hline Emotion & 2.6 & 1.4 & & 2.2 & 1.4 \\
Frustration & 2.9 & 1.6 & & 2.9 & 1.5 \\
Recognition & 0.83 & 0.31 & & 0.68 & 0.43 \\
\hline
\end{tabular}

An emotional priming effect was also found. The rate of TOTs was examined as a function of whether the prior question was emotional or neutral. This was intended to determine whether the emotional arousal elicited by the emotion-inducing questions continued past that individual question. The overall TOT rate in the study was $30 \%$ (regardless of condition). However, on the question following an emotion-inducing question, the TOT rate was $38 \%$. This difference was significant $[t(29)=2.5]$.

\section{Emotionality and Frustration}

These data are displayed in Table 1. Neutral items were given lower emotionality judgments than were the emotional questions $\left[F(1,29)=12.1, M S_{\mathrm{e}}=1.0, \eta^{2}=.29\right]$. TOTs were given higher emotional judgments than were n-TOTs $\left[F(1,29)=112.4, M S_{\mathrm{e}}=0.08, \eta^{2}=.80\right]$. Finally, the interaction between type of question and the presence or absence of TOTs was also significant $[F(1,29)=8.2$, $\left.M S_{\mathrm{e}}=0.80, \eta^{2}=.22\right]$. The interaction appears because the emotionality ratings were particularly high for the emotional questions that received TOTs. Participants were also more likely to use the highest emotional ratings (either 4 or 5 ) in the emotion condition ( $14 \%$ of the time) than in the nonemotional condition $[10 \%$ of the time; $F(1,17)=$ $\left.6.4, M S_{\mathrm{e}}=0.56, \eta^{2}=.27\right]$.

The frustration judgments followed a different pattern. TOTs were given higher frustration judgments than were n-TOTs $\left[F(1,29)=124.0, M S_{\mathrm{e}}=0.41, \eta^{2}=.81\right]$, which was consistent with the idea that TOTs create a sense of frustration with one's inability to recall the target word. However, there was no difference between emotional and neutral questions in rated frustration $(F=1.37)$, and there was no interaction between presence or absence of a TOT and type of question $(F<1)$.

\section{DISCUSSION}

The primary finding is that participants experienced more TOTs for questions that aroused emotion than for those that did not. This finding has three dimensions: First, there were more TOTs for unrecalled emotion-inducing questions than for unrecalled neutral questions. Second, TOTs, especially in the emotion-inducing condition, received higher emotion ratings than did n-TOTs. Third, the emotion induced by an emotional question extended to the next question. TOT rates for questions following an emotion-inducing question (38\%) were higher than the overall TOT rate $(30 \%)$. This last finding is the strongest evidence that emotion affects TOTs, because this difference cannot be explained by any differences unaccounted for between the emotional words and neutral words; neutral items were more likely to be given TOTs if the previous item had been emotional. That is, the emotional arousal created by a previous question persisted to the next question.

In previous research, the direction of the relation between TOTs and emotion was correlational, and it could not be determined whether the TOTs caused the emotion or the emotion caused the TOTs (Schwartz, 2001; Schwartz et al., 2000). In the present study, however, emotionality was an independent variable. Therefore, it is possible to 
conclude that the emotional questions resulted in a greater likelihood of experiencing a TOT for both that question and the one that followed it.

The present findings are consistent with the metacognitive approach to TOTs, because they suggest that nonlinguistic factors, like emotion, influence TOT rates. Perhaps emotional information is more likely to induce TOTs because the experience of emotion is used as a cue to indicate that the person will eventually recall the target word during a retrieval failure. The finding that emotional questions increase TOTs is consistent with other findings that suggest that TOTs are based on clues such as cue familiarity and the retrieval of partial and related information (Metcalfe et al., 1993; Schwartz \& Smith, 1997).

Alternatively, if, at the time of retrieval, one experiences emotion brought on by the question, it is possible that the emotion is mistakenly attributed to the failed recall, rather than correctly attributed to the uncomfortable nature of the question. This mistaken attribution induces the TOT. This idea is supported by the observation that emotional questions primed the participant to feel a TOT for the next question, even if the subsequent question was not itself an emotional one. This may have occurred because the participant erroneously attributed his emotional state to the question, be it emotional or neutral, that followed. The idea that the emotion elicited by the question is attributed to the TOT is similar to effects observed in other aspects of memory in which variables such as fluency are misattributed to memory (Leboe \& Ansons, 2006; Whittlesea \& Leboe, 2003).

The present findings contribute to a growing understanding of TOTs as metacognitive experiences that occur during some failed retrievals. Recent neural findings support the view that TOT is metacognitive in nature. TOTs activate areas of the brain that are associated with metacognitive monitoring and control (see Shimamura, 2008). For example, Maril, Simons, Weaver, and Schacter (2005) found that TOTs were associated with activity in the anterior cingulate, the right dorsolateral prefrontal cortex, and the right inferior prefrontal cortex. These areas appeared unique to TOTs and were not as strongly activated during either "know" or "don't know" responses (also, see Maril, Wagner, \& Schacter, 2001). The anterior cingulate, in addition to its role in TOTs, is also associated with surprise and emotion (see Allman, Hakeem, Erwin, Nimchinsky, $\&$ Hof, 2001), perhaps providing the neural basis for the present findings.

Research on TOTs generally has been concerned either with the role of the TOT in lexical retrieval or with the metacognitive mechanisms responsible for TOTs. However, little data exist to support the idea that TOTs and emotions are related. The present experiment showed that questions that induce emotion also induce more TOTs.

\section{AUTHOR NOTE}

The author thanks Lien Hernandez for her assistance with data collection and Leslie Frazier, Nate Kornell, and two anonymous reviewers for comments on drafts of the manuscript. The FIU Internal Review Board approved the research. Correspondence concerning this article should be addressed to B. Schwartz, Department of Psychology, Florida Inter- national University, University Park, Miami, FL 33199 (e-mail: bennett .schwartz@fiu.edu).

\section{REFERENCES}

Allman, J. M., Hakeem, A., Erwin, J. M., Nimchinsky, E., \& Hof, P. (2001). Anterior cingulate cortex: The evolution of an interface between emotion and cognition. In A. R. Damasio, A. Harrington, \& J. Kagan (Eds.), Unity of knowledge: The convergence of natural and human sciences (Annals of the New York Academy of Sciences, Vol. 935, pp. 105-117). New York: New York Academy of Sciences.

Brennen, T., ViKan, R., \& DybDahl, R. (2007). Are tip-of-the-tongue states universal? Evidence from the speakers of an unwritten language. Memory, 15, 167-176. doi:10.1080/09658210601164743

Brown, A. S. (1991). A review of the tip-of-the-tongue experience. Psychological Bulletin, 109, 204-223. doi:10.1037/0033-2909.109.2.204

Brown, R., \& McNeill, D. (1966). The "tip of the tongue" phenomenon. Journal of Verbal Learning \& Verbal Behavior, 5, 325-337. doi:10.1016/S0022-5371(66)80040-3

Galdo-Alvarez, S., Lindín, M., \& Díaz, F. (2009). The effect of age on event-related potentials (ERP) associated with face naming and the tip-of-the-tongue (TOT) state. Biological Psychology, 81, 14-23. doi:10.1016/j.biopsycho.2009.01.002

Gollan, T. H., \& Brown, A. S. (2006). From tip-of-the-tongue (TOT) data to theoretical implications in two steps: When more TOTs means better retrieval. Journal of Experimental Psychology: General, 135, 462-483. doi:10.1037/0096-3445.135.3.462

KENSINGER, E. A. (2009). How emotion affects older adults' memories for event details. Memory, 17, 208-219. doi:10.1080/09658210802221425

Kensinger, E. A., \& Schacter, D. L. (2008). Memory and emotion. In M. Lewis, J. M. Haviland-Jones, \& L. F. Barrett (Eds.), The handbook of emotion (3rd ed., pp. 601-617). New York: Guilford.

Leboe, J. P., \& Ansons, T. L. (2006). On misattributing good remembering to a happy past: An investigation into the cognitive roots of nostalgia. Emotion, 6, 596-610. doi:10.1037/1528-3542.6.4.596

Maril, A., Simons, J. S., Weaver, J. J., \& Schacter, D. L. (2005). Graded recall success: An event-related fMRI comparison of tip of the tongue and feeling of knowing. NeuroImage, 24, 1130-1138.

Maril, A., Wagner, A. D., \& Schacter, D. L. (2001). On the tip of the tongue: An event-related fMRI study of semantic retrieval failure and cognitive conflict. Neuron, 31, 653-660.

Metcalfe, J., Schwartz, B. L., \& Joaquim, S. G. (1993). The cue familiarity heuristic in metacognition. Journal of Experimental Psychology: Learning, Memory, \& Cognition, 19, 851-861. doi:10.1037/0278 $-7393.19 .4 .851$

Nelson, T. O., \& NARENS, L. (1980). Norms of 300 general-information questions: Accuracy of recall, latency of recall, and feeling-ofknowing ratings. Journal of Verbal Learning \& Verbal Behavior, 19, 338-368. doi:10.1016/S0022-5371(80)90266-2

SchwarTz, B. L. (2001). The relation of tip-of-the-tongue states and retrieval time. Memory \& Cognition, 29, 117-126.

Schwartz, B. L. (2002). Tip-of-the-tongue states: Phenomenology, mechanism, and lexical retrieval. Mahwah, NJ: Erlbaum.

Schwartz, B. L. (2006). Tip-of-the-tongue states as metacognition. Metacognition \& Learning, 1, 149-158.

SchwARTZ, B. L. (2008). Working memory load differentially affects tip-of-the-tongue states and feeling-of-knowing judgment. Memory \& Cognition, 36, 9-19. doi:10.3758/MC.36.1.9

Schwartz, B. L., \& Smith, S. M. (1997). The retrieval of related information influences tip-of-the tongue states. Journal of Memory \& Language, 36, 68-86. doi:10.1006/jmla.1996.2471

Schwartz, B. L., Travis, D. M., Castro, A. M., \& Smith, S. M. (2000). The phenomenology of real and illusory tip-of-the-tongue states. Memory \& Cognition, 28, 18-27.

Shimamura, A. P. (2008). A neurocognitive approach to metacognitive monitoring and control. In J. Dunlosky \& R. A. Bjork (Eds.), Handbook of memory and metamemory: Essays in honor of Thomas $O$. Nelson (pp. 373-390). Mahwah, NJ: Erlbaum.

Smith, S. M. (1994). Frustrated feelings of imminent recall: On the tip of the tongue. In J. Metcalfe \& A. P. Shimamura (Eds.), Metacognition: Knowing about knowing (pp. 27-45). Cambridge, MA: MIT Press. 
Vigliocco, G., Antonini, T., \& Garrett, M. F. (1997). Grammatical gender is on the tip of Italian tongues. Psychological Science, 8, 314317. doi:10.1111/j.1467-9280.1997.tb00444.x

Whittlesea, B. W. A., \& Leboe, J. P. (2003). Two fluency heuristics (and how to tell them apart). Journal of Memory \& Language, 49, 6279. doi:10.1016/S0749-596X(03)00009-3
Wilkinson, T. S., \& Nelson, T. O. (1984). FACTRETRIEVAL2: A Pascal program for assessing someone's recall of general-information facts, confidence about recall correctness, feeling-of-knowing judgments for nonrecalled facts, and recognition of nonrecalled facts. Behavior Research Methods, Instruments, \& Computers, 16, 486-488.

\section{APPENDIX}

Question

Answer

What is the name of the procedure that introduces liquids into the rectum and colon via the anus?

What is the name of the active drug in marijuana and hashish?

What animals were used in the Middle Ages in bloodletting?

What is the French word that translates as "shit?"

What was the name of the largest Nazi concentration camp in Poland?

What town is the birthplace of former Iraqi dictator Saddam Hussein?

Oral sex performed on a man is known by what term?

What is the term for ritual suicide in Japan?

What is the technical name for the bodily function of passing intestinal gas via the anus?

What tool was used to execute people during the French revolution?

What is the sterilization procedure called in which a man's vasa deferentia are cut?

What is the name of the bacteria-borne disease that is used as a biological warfare agent and can also affect domestic animals?

Multiple Choice
kinetosis
halitosis
autonausea
motionphilia
enema
varicosis
pangenisis
analensis
cannabis
LSD
Benzodiazepines
mescalin
leeches
bats
ticks
mosquitoes
merde
dingue
baissez-vou
fou
Auschwitz
Treblinka
Odessa
Kristallnacht
Tikrit
Bagdad
Teheran
Mosul
fellatio
cunnilingus
intercourse
interlingua
seppuku
kamikaze
tapanaki
hiragana
flatulence
embouchure
feces
reflux
guillotine
garrote
dismemberment
gibbet
vasectomy
hemostat
ligation
cyrostorage
anthrax
plague
yaws
syphilis




\section{APPENDIX (Continued)}

\begin{tabular}{|c|c|c|}
\hline Question & Answer & Multiple Choice \\
\hline $\begin{array}{l}\text { What was the name of the ship upon which African-born slaves revolted and } \\
\text { eventually won their freedom when the Supreme Court ruled in their favor? }\end{array}$ & Amistad & $\begin{array}{l}\text { Amistad } \\
\text { Bounty } \\
\text { Freedom } \\
\text { Lancet }\end{array}$ \\
\hline $\begin{array}{l}\text { What is the word that means mercifully killing a person who is terminally ill } \\
\text { and in great pain? }\end{array}$ & euthanasia & $\begin{array}{l}\text { euthanasia } \\
\text { ideation } \\
\text { exsanguination } \\
\text { fratricide }\end{array}$ \\
\hline $\begin{array}{l}\text { What is the name of the painful disease that is caused by the same virus as } \\
\text { chicken pox and attacks people many years after their bout with chicken } \\
\text { pox? }\end{array}$ & shingles & $\begin{array}{l}\text { shingles } \\
\text { herpes } \\
\text { leprosy } \\
\text { cholera }\end{array}$ \\
\hline $\begin{array}{l}\text { What is the last name of the actor who plays "Fat Bastard" in the Austin } \\
\text { Powers movies? }\end{array}$ & Myers & $\begin{array}{l}\text { Myers } \\
\text { Murphy } \\
\text { Carroll } \\
\text { Black }\end{array}$ \\
\hline $\begin{array}{l}\text { What is the last name of the serial killer in New York who went by the names } \\
\text { "Son of Sam" and the "44-caliber killer?" }\end{array}$ & Berkowitz & $\begin{array}{l}\text { Berkowitz } \\
\text { Rifkin } \\
\text { Dahmer } \\
\text { Cheney }\end{array}$ \\
\hline $\begin{array}{l}\text { What is derogatory term for Americans in many Spanish-speaking } \\
\text { countries? }\end{array}$ & gringo & $\begin{array}{l}\text { gringo } \\
\text { flaco } \\
\text { Americano } \\
\text { pocho }\end{array}$ \\
\hline $\begin{array}{l}\text { What is the name of the government building in Washington, D.C. that was } \\
\text { attacked on September } 11,2001 \text { ? }\end{array}$ & Pentagon & $\begin{array}{l}\text { Pentagon } \\
\text { Treasury } \\
\text { Smithsonian } \\
\text { White House }\end{array}$ \\
\hline
\end{tabular}

(Manuscript received May 12, 2009;

revision accepted for publication September 11, 2009.) 